\title{
TERT promoter mutations are associated with distant metastases in papillary thyroid carcinoma
}

\author{
Greta Gandolfi ${ }^{1}$, Moira Ragazzi ${ }^{2}$, Andrea Frasoldati ${ }^{3}$, Simonetta Piana ${ }^{2}$, \\ Alessia Ciarrocchi ${ }^{1}$ and Valentina Sancisi ${ }^{1}$ \\ ${ }^{1}$ Laboratory of Translational Research, ${ }^{2}$ Pathology Unit and ${ }^{3}$ Endocrinology Unit, Arcispedale S. Maria Nuova-IRCCS, \\ Viale Risorgimento 80, 42123 Reggio Emilia, Italy
}

Correspondence should be addressed to A Ciarrocchi Email

Alessia.Ciarrocchi@asmn.re.it

\begin{abstract}
Objective: Transcriptional activating mutations in the promoter of the telomerase reverse transcriptase (TERT) gene were reported at high frequency in aggressive poorly differentiated and anaplastic thyroid cancers. By contrast, the relevance of these mutations in the metastatic behavior of well-differentiated thyroid cancer is still to be defined. The aim of this work was to investigate the frequency of TERT promoter mutations in a remarkable cohort of well-differentiated papillary thyroid carcinoma that developed distant metastases (DM-PTCs) and to establish whether these mutations may be predictive of metastatic behavior.

Design: We analyzed the frequency of TERT promoter mutations in a group of 43 highly aggressive DM-PTCs. As controls, we analyzed these mutations in a group of 78 PTCs without distant metastases (control-PTCs). The possible correlation between TERT promoter mutations and BRAF V600E mutation was also investigated.

Methods: TERT promoter mutational status was evaluated by direct sequencing of the hotspot harboring the C228T and the C250T mutations.

Results: In the overall cohort of 121 PTCs analyzed, $17 \%$ of cases (21/121) carried a mutation in the TERT promoter. Noticeably, $33 \%$ of DM-PTCs were mutated in the TERT promoter while only $9 \%$ of the control-PTCs showed a mutation in this locus.

We also observed a positive association between BRAF V600E and TERT C228T mutations in the cohort of DM-PTCs.

Conclusions: These results indicate that TERT promoter mutations are associated with the development of distant metastases in PTCs and may help in predicting aggressive behavior in this type of tumor.
\end{abstract}

\section{Introduction}

Thyroid tumors are the most common malignancies of the endocrine system and their incidence increased significantly over the past two decades worldwide $(1,2,3)$. Based on histological and cytological features, follicularcell derived tumors are classified into three categories: well-differentiated, poorly differentiated, and anaplastic. Aggressiveness and lethality of these tumors are inversely correlated with the degree of their differentiation (4). Well-differentiated papillary thyroid carcinomas (PTC), the most common type of thyroid cancer, are usually considered indolent lesions with slow rate of growth, low (c) 2015 European Society of Endocrinology Printed in Great Britain metastatic potential, and favorable outcome (up to $95 \%$ of survival after 10 years) $(3,5)$. Nevertheless, the occurrence of aggressively behaving well-differentiated carcinomas is not a rare event and there is an urgent need of more accurate prognostic tools to predict the spread of these lesions to distant sites in the early phases of diagnosis. Besides age, the presence of distant metastases, occurring in a small percentage $(\sim 10 \%)$ of the entire PTC population $(5,6,7)$, represents the major clinical feature reliably associated with a negative outcome of PTC patients. During progression from local to metastatic

Published by Bioscientifica Ltd. 
Table 1 Clinical and pathological features of well-differentiated papillary thyroid carcinomas with distant metastases (DM-PTCs) or without distant metastases (control-PTCs) used in this study.

\begin{tabular}{l}
\hline Clinico-pathological features \\
\hline Total \\
Mean follow-up, months (range) \\
Mean age at diagnosis, years (range) \\
Sex \\
Females \\
Males \\
Histological diagnosis \\
CPTCs \\
TCV-PTCs \\
FV-PTCs \\
SD-PTCs \\
ST-PTCs \\
Pathologic stage at presentation \\
I \\
II \\
III \\
IV \\
Vascular invasion \\
Present \\
Absent \\
NA \\
Follow-up status \\
NED \\
AWD \\
DOD \\
DOC \\
\end{tabular}

\begin{tabular}{c}
\hline DM-PTCs \\
\hline 43 \\
$102.1 \pm 76.8(2-391)$ \\
$54.8 \pm 19.1(19-90)$ \\
$28(0.65)$ \\
$15(0.35)$ \\
$20(0.46)$ \\
$15(0.35)$ \\
$6(0.14)$ \\
0 \\
$2(0.05)$ \\
$2(0.05)$ \\
$9(0.21)$ \\
$7(0.16)$ \\
$25(0.58)$ \\
\\
$29(0.76)$ \\
$9(0.24)$ \\
5 \\
$5(0.12)$ \\
$16(0.37)$ \\
$22(0.51)$ \\
0 \\
\end{tabular}

\begin{tabular}{|c|c|}
\hline Control-PTCs & $P$ value \\
\hline $\begin{array}{c}78 \\
136.3 \pm 59.2(15-369) \\
44.4 \pm 16.8(16-78)\end{array}$ & $\begin{array}{l}0.01 \\
0.003\end{array}$ \\
\hline $\begin{array}{l}55(0.71) \\
23(0.29)\end{array}$ & 0.54 \\
\hline $\begin{array}{c}45(0.58) \\
20(0.26) \\
9(0.12) \\
2(0.03) \\
1(0.01)\end{array}$ & 0.39 \\
\hline $\begin{array}{c}47(0.60) \\
4(0.05) \\
18(0.23) \\
9(0.12)\end{array}$ & $<0.001$ \\
\hline $\begin{array}{c}24(0.40) \\
36(0.60) \\
18\end{array}$ & $<0.001$ \\
\hline $\begin{array}{c}66(0.85) \\
2(0.02) \\
0 \\
10(0.13)\end{array}$ & $<0.001$ \\
\hline
\end{tabular}

CPTC, classic PTC; TCV-PTC, tall cell-variant PTC; FV-PTC, follicular-variant PTC; SD-PTC, sclerosing diffuse PTC; ST-PTC, solid trabecular PTC. NED, alive with no evidence of disease; AWD, alive with disease ( ${ }^{A}$ alive with metastatic disease in DM-PTCs or alive with neck recurrence in control-PTCS); DOD, dead of disease; DOC, dead of other causes.

a Vascular invasion was defined as the presence of intravascular tumor cells either covered by endothelium or associated with thrombus, affecting lymphatic or blood vessels, and was analyzed in 38 DM-PTCs and in 60 control-PTCs.

disease, tumor cells change their genomic profile to acquire adaptive aggressive features. Owing to the low frequency of distantly metastatic PTCs, very little is currently known on the genetic alterations that occur during the spreading to distant sites of these tumors.

Unlimited replicative potential is a major hallmark of cancer cells (8). As a consequence of the high rate of proliferation, the telomere repeats length tends to shorten very rapidly in cancer cells. Telomerase is a large protein complex which protects the telomere repeats from erosion, thus antagonizing replicative senescence and apoptosis $(9,10)$. Indeed, abnormal function of telomerase has been described as a common feature in several types of cancer (11). Telomerase activity is mainly dependent on the expression of its rate-limiting catalytic subunit, namely the telomerase reverse transcriptase (TERT). Recently, mutations in the promoter of TERT gene were described to occur with high frequency in different types of solid tumors $(12,13,14,15,16,17,18,19,20,21,22)$. In particular, TERT promoter mutations were mainly found in two hot spots in positions - 124 bp (chr5: 1295228 $\mathrm{G}>\mathrm{A}$, hereafter termed C228T) and $-146 \mathrm{bp}$ (chr5: $1295250 \mathrm{G}>\mathrm{A}$, hereafter termed C250T) upstream the gene transcription starting site. These alterations were

Table 2 Occurrence and frequencies of TERT promoter mutations in well-differentiated papillary thyroid carcinomas with distant metastases (DM-PTCs) or without distant metastases (control-PTCs).

\begin{tabular}{|c|c|c|c|}
\hline & Total PTCs & DM-PTCs & Control-PTCs \\
\hline$n$ & 121 & 43 & 78 \\
\hline $\begin{array}{r}n \text { PTCs mutated in TERT } \\
\text { promoter (frequency) }\end{array}$ & $21(0.17)$ & $14(0.33)^{a}$ & $7(0.09)^{a}$ \\
\hline \multicolumn{4}{|l|}{ Type of mutation } \\
\hline C228T & $12(0.10)$ & $11(0.26)$ & $1(0.013)$ \\
\hline C250T & $5(0.04)$ & $3(0.07)$ & $2(0.025)$ \\
\hline CC228-229TT & $2(0.02)$ & 0 & $2(0.025)$ \\
\hline C229T & $1(<0.01)$ & 0 & $1(0.013)$ \\
\hline C232T & $1(<0.01)$ & 0 & $1(0.013)$ \\
\hline
\end{tabular}

$P$ value $=0.002$

${ }^{\mathrm{a}}$ Fisher's exact test between TERT mutation frequencies in DM-PTCS and control-PTCs. 
found to increase promoter activity and TERT expression, most likely introducing new consensus sites for transcription factors belonging to the ETS family.

TERT promoter mutations were also described in thyroid cancer, where C228T represents the most common mutation. The frequency of TERT promoter mutations is quite low in well-differentiated thyroid cancer (7.5-25\% depending on series), but it increases significantly from well to poorly differentiated and undifferentiated carcinomas, up to $50 \%$ of all cases, indicating a strong association of these mutations with the aggressiveness and the metastatic spreading of thyroid malignancy $(23,24,25,26,27,28)$.

The aim of this work was to assess the occurrence and the frequency of TERT promoter mutations in a large cohort of PTCs that developed distant metastases and to establish whether the presence of these mutations may hold promise of useful prognostic biomarker in this type of cancer.

\section{Subjects and methods}

\section{Patient selection}

For this study, 43 cases of aggressive well-differentiated PTCs that developed distant metastases outside the neck (mainly in lungs, brain, and bones; DM-PTCs) were retrieved from the Thyroid Tumor archive of the Pathology Unit of the Arcispedale S. Maria Nuova, which comprises 2200 cases of thyroid cancers diagnosed from 1979 to 2013. From the same archive, 78 control PTCs without distant metastases were retrieved. Of those, 47 PTCs developed neck lymph node metastases (LNMs), while 31 did not develop LNMs and were confined to the thyroid gland.

Tumor cases were screened by two authors (S Piana and M Ragazzi) and classified according to the criteria recommended by the World Health Organization Classification of Tumors (29), in order to exclude high-grade carcinomas, and staged according to AJCC Cancer Staging Manual, 7th edition (30).

Control samples were not consecutive cases and were selected according to the metastases status ( $\mathrm{NO}$ or $\mathrm{N} 1$ and M0) and to the clinical data and tissue availability. It was not possible to obtain matched pair for age, due to the average older age of DM-PTCs patients.

In addition, 16 LNMs derived from 15 of the primary PTCs cases described above were retrieved from the archive. These included ten LNMs from nine primary
DM-PTCs (two LNMs derived from a single primary DM-PTCs) and six LNMs from six primary control-PTCs.

Part of these samples corresponded to the cases described in previous studies $(31,32)$. All the patients underwent total thyroidectomy and in $80 \%$ of the cases they underwent also ipsilateral central neck dissection. Average follow-up time for all cases was 124.1 \pm 67.7 months. Clinical and pathological features of DM-PTCs and control cases are summarized in Table 1 . This project has been approved by the Local Ethics Committee.

\section{Tissues selection and genomic DNA extraction}

Genomic DNA was extracted from five $5 \mu \mathrm{m}$-thick slices of formalin-fixed and paraffin-embedded PTCs and LNMs samples, by using the Biostic FFPE Tissue DNA Isolation Kit (MoBio Laboratories, Inc., Carlsbad, CA, USA). The tumor samples were manually dissected under microscopic guidance by the pathologists M Ragazzi and S Piana and any nontumoral tissue surrounding the tumor was pared away.

\section{TERT promoter mutation analysis}

The TERT promoter mutations were analyzed by PCR amplification and direct Sanger sequencing of the hot spots was previously described. Briefly, a 231-bp region of the TERT promoter containing the position of C228T and

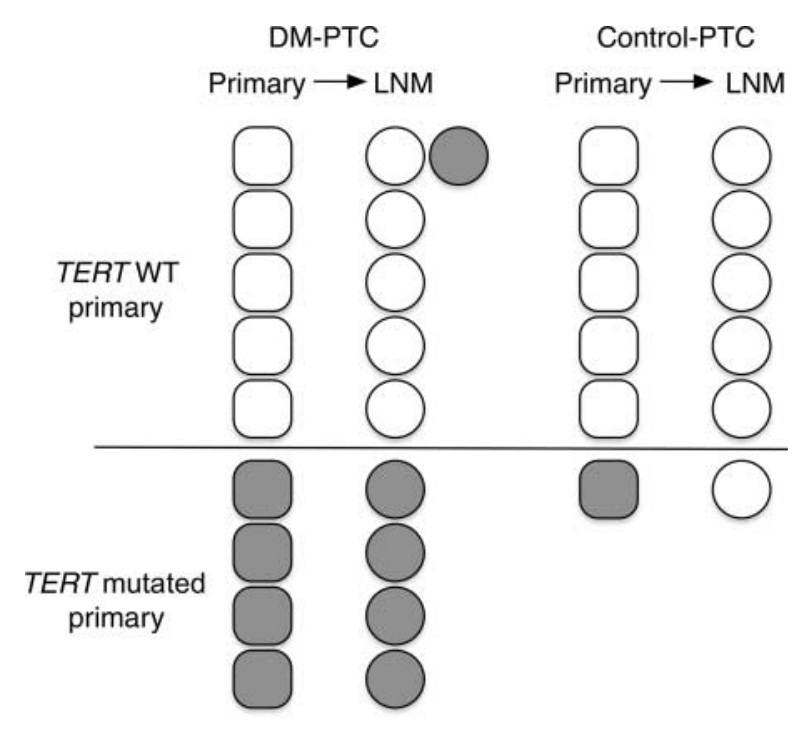

\section{Figure 1}

TERT promoter mutation status in matched primary PTCs (squares) and lymph node metastases (LNMs, circles). Gray shapes are TERT C228T mutated and white shades are WT. 
Table 3 Association between TERT promoter mutation and clinical and pathological features in well-differentiated PTCs with distant metastases (DM-PTCs) and in PTCs without distant metastases (control-PTCs).

\begin{tabular}{|c|c|c|c|}
\hline & TERT WT & $\begin{array}{c}\text { TERT } \\
\text { mutated }\end{array}$ & $P$ value \\
\hline Total PTCs $(n=121)$ & $n=100$ & $n=21$ & \\
\hline Age at diagnosis (years) & $45.6 \pm 17.6$ & $59.8 \pm 17.1$ & 0.001 \\
\hline Sex & & & 0.8 \\
\hline Females & $69(0.69)$ & $14(0.66)$ & \\
\hline Males & $31(0.31)$ & $7(0.33)$ & \\
\hline Histological diagnosis & & & 0.03 \\
\hline CPTCs & $60(0.60)$ & $6(0.29)$ & \\
\hline TCV-PTCS & $24(0.24)$ & $11(0.52)$ & \\
\hline FV-PTCs & $13(0.13)$ & $2(0.09)$ & \\
\hline SD-PTCS & $1(0.01)$ & $1(0.05)$ & \\
\hline ST-PTCS & $2(0.02)$ & $1(0.05)$ & \\
\hline \multicolumn{2}{|c|}{ Pathologic stage at presentation } & & 0.02 \\
\hline I & $46(0.46)$ & $3(0.14)$ & \\
\hline II & $11(0.11)$ & $2(0.10)$ & \\
\hline III & $20(0.20)$ & $5(0.24)$ & \\
\hline IV & $23(0.23)$ & $11(0.52)$ & \\
\hline Vascular invasion $(n=98)$ & & & 0.9 \\
\hline Present & $42(0.53)$ & $11(0.58)$ & \\
\hline Follow-up status & & & 0.001 \\
\hline NED & $66(0.66)$ & $5(0.24)$ & \\
\hline $\mathrm{AWD}^{\mathrm{A}}$ & $14(0.14)$ & $4(0.19)$ & \\
\hline DOD & $13(0.13)$ & $9(0.43)$ & \\
\hline DOC & $7(0.07)$ & $3(0.14)$ & \\
\hline Distant metastases & & & 0.002 \\
\hline Present & $29(0.29)$ & $14(0.67)$ & \\
\hline LNMs & & & 0.27 \\
\hline Present & $72(0.72)$ & $18(0.85)$ & \\
\hline DM-PTCs $(n=43)$ & $n=29$ & $n=14$ & \\
\hline Age at diagnosis (years) & $50 \pm 19.2$ & $64.9 \pm 14.7$ & 0.02 \\
\hline \multicolumn{4}{|l|}{ Sex } \\
\hline Females & $19(0.66)$ & $9(0.64)$ & 1 \\
\hline Males & $10(0.34)$ & $5(0.36)$ & \\
\hline \multicolumn{4}{|l|}{ Histological diagnosis } \\
\hline CPTCs & $17(0.59)$ & $3(0.22)$ & 0.06 \\
\hline TCV-PTCs & $7(0.24)$ & $8(0.57)$ & \\
\hline FV-PTCs & $4(0.14)$ & $2(0.14)$ & \\
\hline SD-PTCS & 0 & 0 & \\
\hline ST-PTCS & $1(0.03)$ & $1(0.07)$ & \\
\hline \multicolumn{4}{|c|}{ Pathologic stage at presentation } \\
\hline I & $2(0.07)$ & $0(0.0)$ & 0.32 \\
\hline II & $8(0.27)$ & $1(0.07)$ & \\
\hline III & $4(0.14)$ & $3(0.21)$ & \\
\hline IV & $15(0.52)$ & $10(0.72)$ & \\
\hline Vascular invasion $(n=38)$ & & & 0.73 \\
\hline Present & $20(0.80)$ & $9(0.69)$ & \\
\hline \multicolumn{4}{|l|}{ Follow-up status } \\
\hline NED & $4(0.14)$ & $1(0.07)$ & 0.57 \\
\hline$A W D^{A}$ & $12(0.41)$ & $4(0.29)$ & \\
\hline DOD & $13(0.45)$ & $9(0.64)$ & \\
\hline DOC & 0 & 0 & \\
\hline Control-PTCs $(n=78)$ & $n=71$ & $n=7$ & \\
\hline Age at diagnosis (years) & $43.8 \pm 16.7$ & $49.9 \pm 18.4$ & 0.38 \\
\hline Sex & & & 1 \\
\hline Females & $50(0.70)$ & $5(0.71)$ & \\
\hline Males & $21(0.30)$ & $2(0.29)$ & \\
\hline Histological diagnosis & & & 0.2 \\
\hline
\end{tabular}

Table 3 Continued.

\begin{tabular}{|c|c|c|c|}
\hline & TERT WT & $\begin{array}{c}\text { TERT } \\
\text { mutated }\end{array}$ & $P$ value \\
\hline CPTCs & $43(0.60)$ & $3(0.43)$ & \\
\hline TCV-PTCs & $17(0.24)$ & $3(0.43)$ & \\
\hline FV-PTCs & $9(0.13)$ & 0 & \\
\hline SD-PTCs & $1(0.015)$ & $1(0.14)$ & \\
\hline ST-PTCs & $1(0.015)$ & 0 & \\
\hline \multicolumn{3}{|c|}{ Pathologic stage at presentation } & 0.61 \\
\hline I & $44(0.62)$ & $3(0.43)$ & \\
\hline II & $3(0.04)$ & $1(0.14)$ & \\
\hline III & $16(0.23)$ & $2(0.29)$ & \\
\hline IV & $8(0.11)$ & $1(0.14)$ & \\
\hline Vascular invasion $(n=60)$ & & & 1 \\
\hline Present & $22(0.41)$ & $2(0.33)$ & \\
\hline Follow-up status & & & 0.04 \\
\hline NED & $62(0.87)$ & $4(0.57)$ & \\
\hline$A W D^{A}$ & $2(0.03)$ & 0 & \\
\hline DOD & 0 & 0 & \\
\hline DOC & $7(0.10)$ & $3(0.43)$ & \\
\hline \multicolumn{4}{|l|}{ LNMs } \\
\hline Present & $43(0.61)$ & $4(0.57)$ & 1 \\
\hline
\end{tabular}

CPTC, classic PTC; TCV-PTC, tall cell-variant PTC; FV-PTC, follicular-variant PTC; SD-PTC, sclerosing diffuse PTC; ST-PTC, solid trabecular PTC; NED, alive with no evidence of disease; AWD, alive with disease ( ${ }^{A}$ alive with metastatic disease in DM-PTCs or alive with neck recurrence in controlPTCS); DOD, dead of disease; DOC, dead of other causes.

C250T mutations was PCR-amplified using 40-50 ng of genomic DNA: the forward primer 5'-GGATTCGCGGGCACAGAC- $3^{\prime}$ and the reverse primer $5^{\prime}$-AGCGCTGCCTGAAACTCG-3'. The nested-PCR protocol consisted of two steps, each comprising an initial denaturation of $3 \mathrm{~min}$ at $94^{\circ} \mathrm{C}$ and 35 amplification cycles (denaturation for $30 \mathrm{~s}$ at $94^{\circ} \mathrm{C}$, annealing for $30 \mathrm{~s}$ at 60 and $65^{\circ} \mathrm{C}$, and extension for $30 \mathrm{~s}$ at $72^{\circ} \mathrm{C}$ ). Purified PCR products were subjected to standard dye-terminator sequencing using the Genome Laboratory DTCS Quick Start Kit (Beckman Coulter, Inc., Fullerton, CA, USA) and a CEQ 8000 Genetic Analysis System (Beckman Coulter, Inc.).

\section{Statistical analysis}

Statistical analyses were performed by R Statistical Software Package (R Foundation for Statistical Computing, Vienna, Austria; http://www.R-project.org). Data are reported as frequencies or as mean \pm s.D., and TERT promoter mutations frequencies were compared between groups by Fisher's exact test.

The Mann-Whitney-Wilcoxon test (for continuous variables), the $\chi^{2}$ test (for categorical variables with more than two categories), and Fisher's exact test (for categorical variables with two categories) were used to compare the clinicopathological parameters between TERT-mutated 
and TERT-WT PTCs. The same tests were used for the comparison between PTCs without BRAF or TERT mutations and the following three groups: PTCs with only TERT mutations, PTCs with only BRAF mutation, and PTCs with TERT and BRAF mutations coexistence).

Survival curves were plotted by the Kaplan-Meier method with the log-rank statistics. In the survival analysis, only deaths attributable to the thyroid carcinoma (disease-specific mortality) were considered. $P<0.05$ values were considered as threshold for significance.

\section{Results}

\section{TERT promoter is frequently mutated in aggressive PTCs with distant metastases}

The mutational status of a hotspot region within TERT promoter was analyzed in a cohort of 121 PTC, including 43 aggressive PTCs with distant metastases outside the neck and 78 control-PTCs.

The DM-PTC group showed older mean age at diagnoses, higher pathological stage at presentation, higher incidence of vascular invasion, and worse status at follow up compared with the control group, while the two groups did not differ for gender and histotype frequencies (Table 1).

Table 2 gives the results of the mutation analysis. TERT promoter mutations were found in 21 out of 121 PTCs, corresponding to $17 \%$ of the overall cohort. We identified four different TERT promoter mutations, occurring in a mutually exclusive manner. Mutation C228T was the most frequent alteration (found in 10\% of all cases) followed by the C250T mutation (4\% of all cases). Double mutation CC228-229TT was found in two cases and the mutations C229T and C232T were found in one sample each. This latter has never been previously reported. The relative frequency among the detected mutations is in line with the available data in thyroid cancer $(23,24)$.

We observed a strikingly higher frequency of TERT promoter mutations in the group of DM-PTCs compared with controls. Indeed, 14 out of 43 DM-PTCs, corresponding to $33 \%$ of cases, harbored TERT promoter mutations. By contrast, only seven out of 78 control-PTCs were TERTmutated, corresponding to $9 \%$ of cases. This difference was statistically significant (Fisher's exact test; $P=0.002$ ). In the DM-PTCs group, only the C228T and C250T mutations were found, with C228T by far being the most frequent alteration (corresponding to $78.6 \%$ of detected mutations). In the control-PTCs group the different mutations were evenly distributed.

\section{TERT promoter mutation is not associated with the development of LNMs}

Within the control-PTCs group, 47 cases developed neck LNMs while 31 were confined to the thyroid. We did not observe any difference in the occurrence of TERT mutations between these two subgroups. Indeed, four out of the 47 PTCs with LNMs displayed TERT promoter mutations (frequency: 0.08), while three TERT-mutated PTCs were detected in the group of 31 PTCs without LNMs (frequency: $0.10 ; P=0.99)$. In order to evaluate the correspondence of TERT mutational status between primary and matched LNMs, we analyzed 16 LNM samples originated from 15 primary PTCs, including ten WT and five TERT-mutated cases (Fig. 1). We observed correspondence in the TERT genotype in all but two LNM samples, in which the mutation was respectively lost or acquired at the metastatic site. Intriguingly, one of these cases was a WT DM-PTCs, which developed two subsequent LNMs before the distant spreading of the disease. Of these two LNMs, the earlier was TERT-WT while the later had acquired the C228T mutation. This observation seems to suggest that, even if not commonly, TERT promoter mutations can be acquired in late phases of tumor progression.

\section{TERT promoter mutations are associated with aggressive clinico-pathological features of PTCs}

Table 3 shows the results of the association analysis between TERT promoter mutations and different clinicopathological features of PTCs. In the overall cohort of 121 samples, TERT promoter mutations were significantly associated with older age, tall cell-variant (TCV) histotype, advanced stage, DM occurrence, and worse outcome.

Table 4 Association between the occurrences of TERT promoter mutations and BRAF V600E mutation in welldifferentiated PTCs.

\begin{tabular}{|c|c|c|c|}
\hline & BRAF + & BRAF- & $P$ value \\
\hline \multicolumn{4}{|l|}{ Total PTCs } \\
\hline TERT C228T & $9 / 54(0.16)$ & $5 / 67(0.07)$ & NS \\
\hline TERT C250T & $2 / 54(0.04)$ & $3 / 67(0.04)$ & NS \\
\hline TERT all mutations & $12 / 54(0.22)$ & $9 / 67(0.13)$ & NS \\
\hline \multicolumn{4}{|l|}{ DM-PTCs } \\
\hline TERT C228T & $7 / 15(0.46)$ & $4 / 28(0.14)$ & 0.03 \\
\hline TERT C250T & $0 / 15(0.0)$ & $3 / 28(0.11)$ & - \\
\hline TERT all mutations & $7 / 15(0.46)$ & $7 / 28(0.25)$ & NS \\
\hline \multicolumn{4}{|l|}{ Control-PTCs } \\
\hline TERT C228T & 2/39 (0.05) & $1 / 39(0.03)$ & NS \\
\hline TERT C250T & 2/39 (0.05) & $0 / 39(0.0)$ & - \\
\hline TERT all mutations & $5 / 39(0.13)$ & $2 / 39(0.05)$ & NS \\
\hline
\end{tabular}


Table 5 Association of TERT promoter mutations, BRAF V600E mutation, and their coexistence with clinical and pathological features in the total cohort of well-differentiated PTCs, in PTCs with distant metastases (DM-PTCs), and in PTCs without distant metastases (control-PTCs).

\begin{tabular}{|c|c|c|c|c|c|c|c|}
\hline & No mutation & $\begin{array}{l}\text { Only TERT } \\
\text { mutation }\end{array}$ & $\boldsymbol{P}$ & $\begin{array}{l}\text { Only BRAF } \\
\text { mutation }\end{array}$ & $\boldsymbol{P}$ & $\begin{array}{c}\text { TERT }+ \text { BRAF } \\
\text { mutation }\end{array}$ & $\boldsymbol{P}$ \\
\hline Total PTCs $(n=121)$ & $n=58$ & $n=9$ & & $n=42$ & & $n=12$ & \\
\hline Age at diagnosis (years) & $42.8 \pm 17.2$ & $53.7 \pm 20.9$ & 0.09 & $49.5 \pm 17.5$ & 0.06 & $64.5 \pm 12.7$ & 0.0004 \\
\hline Sex & & & 0.88 & & & & 0.70 \\
\hline Females & $40(0.69)$ & $7(0.78)$ & & $29(0.69)$ & 1 & $7(0.58)$ & \\
\hline Males & $18(0.31)$ & $2(0.22)$ & & $13(0.31)$ & & $5(0.41)$ & \\
\hline Histological diagnosis & & & 0.28 & & 0.03 & & 0.0003 \\
\hline CPTCs & $37(0.64)$ & $3(0.33)$ & & $23(0.55)$ & & $3(0.25)$ & \\
\hline TCV-PTCs & $8(0.14)$ & $2(0.22)$ & & $16(0.38)$ & & $9(0.75)$ & \\
\hline FV-PTCs & $10(0.17)$ & $2(0.22)$ & & $3(0.07)$ & & 0 & \\
\hline SD-PTCS & $1(0.02)$ & $1(0.11)$ & & 0 & & 0 & \\
\hline ST-PTCs & $2(0.03)$ & $1(0.11)$ & & 0 & & 0 & \\
\hline Pathologic stage at presentation & & & 0.43 & & 0.15 & & 0.03 \\
\hline I & $27(0.47)$ & $2(0.22)$ & & $19(0.45)$ & & $1(0.08)$ & \\
\hline II & $9(0.15)$ & $1(0.11)$ & & $2(0.05)$ & & $1(0.08)$ & \\
\hline III & $8(0.14)$ & $2(0.22)$ & & $12(0.29)$ & & $3(0.25)$ & \\
\hline IV & $14(0.24)$ & $4(0.44)$ & & $9(0.21)$ & & $7(0.59)$ & \\
\hline Vascular invasion $(n=98)$ & & & 0.45 & & 0.26 & & 0.31 \\
\hline Present & $19(0.59)$ & $7(0.78)$ & & $15(0.45)$ & & $4(0.40)$ & \\
\hline Follow-up status & & & 0.12 & & 0.16 & & 0.002 \\
\hline NED & $37(0.64)$ & $3(0.33)$ & & $29(0.69)$ & & $2(0.17)$ & \\
\hline$A W D^{A}$ & $11(0.19)$ & $2(0.22)$ & & $3(0.07)$ & & $2(0.17)$ & \\
\hline DOD & $8(0.14)$ & $4(0.44)$ & & $5(0.12)$ & & $5(0.41)$ & \\
\hline DOC & $2(0.03)$ & 0 & & $5(0.12)$ & & $3(0.25)$ & \\
\hline Distant metastases & & & 0.02 & & 0.07 & & 0.20 \\
\hline Present & $21(0.36)$ & $7(0.78)$ & & $8(0.19)$ & & $7(0.58)$ & \\
\hline LNMs & & & 0.10 & & 1 & & 1 \\
\hline Present & $42(0.72)$ & $9(1)$ & & $30(0.71)$ & & $9(0.75)$ & \\
\hline DM-PTCs $(n=43)$ & $n=21$ & $n=7$ & & $n=8$ & & $n=7$ & \\
\hline Age at diagnosis (years) & $47.7 \pm 16.8$ & $61.4 \pm 16.1$ & 0.04 & $55.7 \pm 24.9$ & 0.28 & $68.2 \pm 13.2$ & 0.01 \\
\hline Sex & & & 0.66 & & 0.20 & & 1 \\
\hline Females & $12(0.57)$ & $5(0.71)$ & & $7(0.87)$ & & $4(0.57)$ & \\
\hline Males & $9(0.43)$ & $2(0.29)$ & & $1(0.13)$ & & $3(0.43)$ & \\
\hline Histological diagnosis & & & 1 & & 1 & & 0.31 \\
\hline CPTCs & $14(0.67)$ & $2(0.29)$ & & $3(0.38)$ & & $1(0.14)$ & \\
\hline TCV-PTCS & $2(0.09)$ & $2(0.29)$ & & $5(0.62)$ & & $6(0.86)$ & \\
\hline FV-PTCs & $4(0.19)$ & $2(0.29)$ & & 0 & & 0 & \\
\hline ST-PTCs & $1(0.05)$ & $1(0.13)$ & & 0 & & 0 & \\
\hline Pathologic stage at presentation & & & 0.55 & & 0.58 & & 0.37 \\
\hline I & $1(0.05)$ & 0 & & $1(0.13)$ & & 0 & \\
\hline II & $6(0.29)$ & $1(0.14)$ & & $2(0.25)$ & & 0 & \\
\hline III & $2(0.09)$ & $2(0.29)$ & & $2(0.25)$ & & $1(0.14)$ & \\
\hline IV & $12(0.57)$ & $4(0.57)$ & & $3(0.37)$ & & $6(0.86)$ & \\
\hline Vascular invasion $(n=38)$ & & & 1 & & 0.6 & & 0.13 \\
\hline Present & $15(0.83)$ & $6(0.86)$ & & $5(0.71)$ & & $3(0.50)$ & \\
\hline Follow-up status & & & 0.64 & & 0.47 & & 0.26 \\
\hline NED & $3(0.14)$ & $1(0.14)$ & & $1(0.12)$ & & 0 & \\
\hline$A W D^{A}$ & $10(0.48)$ & $2(0.29)$ & & $2(0.25)$ & & $2(0.29)$ & \\
\hline DOD & $8(0.38)$ & $4(0.57)$ & & $5(0.63)$ & & $5(0.71)$ & \\
\hline Control-PTCs $(n=78)$ & $n=37$ & $n=2$ & & $n=34$ & & $n=5$ & \\
\hline Age at diagnosis (years) & $40.0 \pm 17.0$ & $26.5 \pm 6.3$ & 0.29 & $48.0 \pm 15.5$ & 0.03 & $59.2 \pm 10.2$ & 0.02 \\
\hline Sex & & & 1 & & 0.43 & & 0.59 \\
\hline Females & $28(0.76)$ & $2(1)$ & & $22(0.65)$ & & $3(0.60)$ & \\
\hline Males & $9(0.24)$ & 0 & & $12(0.35)$ & & $2(0.40)$ & \\
\hline Histological diagnosis & & & 0.06 & & 0.33 & & 0.25 \\
\hline CPTCs & $23(0.62)$ & $1(0.50)$ & & $20(0.59)$ & & $2(0.40)$ & \\
\hline TCV-PTCs & $6(0.16)$ & 0 & & $11(0.32)$ & & $3(0.60)$ & \\
\hline FV-PTCs & $6(0.16)$ & 0 & & $3(0.09)$ & & 0 & \\
\hline
\end{tabular}


Table 5 Continued.

\begin{tabular}{|c|c|c|c|c|c|c|c|}
\hline & No mutation & $\begin{array}{l}\text { Only TERT } \\
\text { mutation }\end{array}$ & $\boldsymbol{P}$ & $\begin{array}{l}\text { Only BRAF } \\
\text { mutation }\end{array}$ & $\boldsymbol{P}$ & $\begin{array}{c}\text { TERT }+ \text { BRAF } \\
\text { mutation }\end{array}$ & $\boldsymbol{P}$ \\
\hline SD-PTCs & $1(0.03)$ & $1(0.50)$ & & 0 & & 0 & \\
\hline ST-PTCs & $1(0.03)$ & 0 & & 0 & & 0 & \\
\hline Pathologic stage at presentation & & & 0.84 & & 0.06 & & 0.17 \\
\hline I & $26(0.70)$ & $2(1)$ & & $18(0.53)$ & & $1(0.20)$ & \\
\hline II & $3(0.08)$ & 0 & & 0 & & $1(0.20)$ & \\
\hline III & $6(0.16)$ & 0 & & $10(0.29)$ & & $2(0.40)$ & \\
\hline IV & $2(0.06)$ & 0 & & $6(0.18)$ & & $1(0.20)$ & \\
\hline Vascular invasion $(n=60)$ & & & 1 & & 0.78 & & 0.63 \\
\hline Present & $12(0.43)$ & $1(0.50)$ & & $10(0.38)$ & & $1(0.25)$ & \\
\hline Follow-up status & & & 0.91 & & 0.41 & & 0.001 \\
\hline NED & $34(0.92)$ & $2(1)$ & & $28(0.82)$ & & $2(0.40)$ & \\
\hline$A W D^{A}$ & $1(0.03)$ & 0 & & $1(0.03)$ & & 0 & \\
\hline DOC & $2(0.05)$ & 0 & & $5(0.15)$ & & $3(0.60)$ & \\
\hline LNMs & & & 0.50 & & 0.63 & & 0.64 \\
\hline Present & $21(0.57)$ & $2(1)$ & & $22(0.65)$ & & $2(0.4)$ & \\
\hline
\end{tabular}

$P$ values refer to the comparison of the no mutation group with the group in the column at the left of the $P$ value. CPTC, classic PTC; TCV-PTC, tall cell-variant PTC; FV-PTC, follicular-variant PTC; SD-PTC, sclerosing diffuse PTC; ST-PTC, solid trabecular PTC; NED, alive with no evidence of disease; AWD, alive with disease ( ${ }^{A}$ alive with metastatic disease in DM-PTCs or alive with neck recurrence in control-PTCs); DOD, dead of disease; DOC, dead of other causes.

As this cohort of samples was selected in order to have a representative number of aggressive PTCs with distant metastases, it is likely that this association may reflect the higher frequency of this mutation within the DM-PTC group. Indeed, when we performed this analysis in DM-PTCs and control-PTCs groups independently, only age at diagnosis remained significantly associated with the presence of TERT mutations in the DM-PTCs group, while no significant association was observed in the control group.

\section{Association of TERT promoter mutations, BRAF V600E mutation, and their coexistence with clinico-pathological features of PTCs}

The BRAF V600E mutation is the most common genetic alteration in PTCs, with a frequency of about $50 \%$ among all cases. Recently, a possible association between this mutation and the occurrence of TERT promoter mutations has been described and a biological cooperation between these alterations has been suggested (33). Thus, we investigated the association between the occurrence of TERT promoter mutations and BRAF V600E (Table 4). BRAF V600E mutation was present in 54 of the 121 PTC samples analyzed (frequency: 0.44). As previously described, no association between the occurrence of this mutation and the presence of distant metastases was detected $(31,32)$. An association between the presence of TERT C228T and BRAF V600E was observed in the DM-PTCs group (46\% of TERT C228T-mutated in BRAFpositive cases vs $14 \%$ in BRAF-negative cases; $P=0.03$ ). By contrast, the two mutations did not result associated in either the control group or the overall population in analysis, probably due to the small number of TERT mutated cases in the control group.

In the overall cohort of 121 samples, the coexistence of TERT promoter mutations and BRAF V600E mutation was significantly associated with older age, TCV histotype, advanced stage, and worse outcome. TERT mutation alone remained independently associated with the presence of distant metastases. Within the DM-PTCs group, TERT mutations were associated with older age, either alone or in association with BRAF V600E. By contrast, in the control-PTCs group, the BRAF V600E was associated with older age, either alone or in association with TERT promoter mutations (Table 5).

\section{Effect of TERT promoter mutations on thyroid cancer- specific survival}

Next, we investigated the effect of TERT promoter mutations on the survival of PTCs patients. The Kaplan-Meier survival analysis showed that the presence of TERT promoter mutations was strongly associated with increased disease-specific mortality in the overall PTCs cases analyzed ( $\log$-rank $P=0.001$; Fig. 2A). However, the same analysis performed within the DM-PTCs showed no statistically significant difference in the survival curves (Fig. 2B).

When we analyzed the survival curves by TERT mutation, BRAF mutation, and their coexistence status in the overall PTCs cases, we found that PTCs with either 

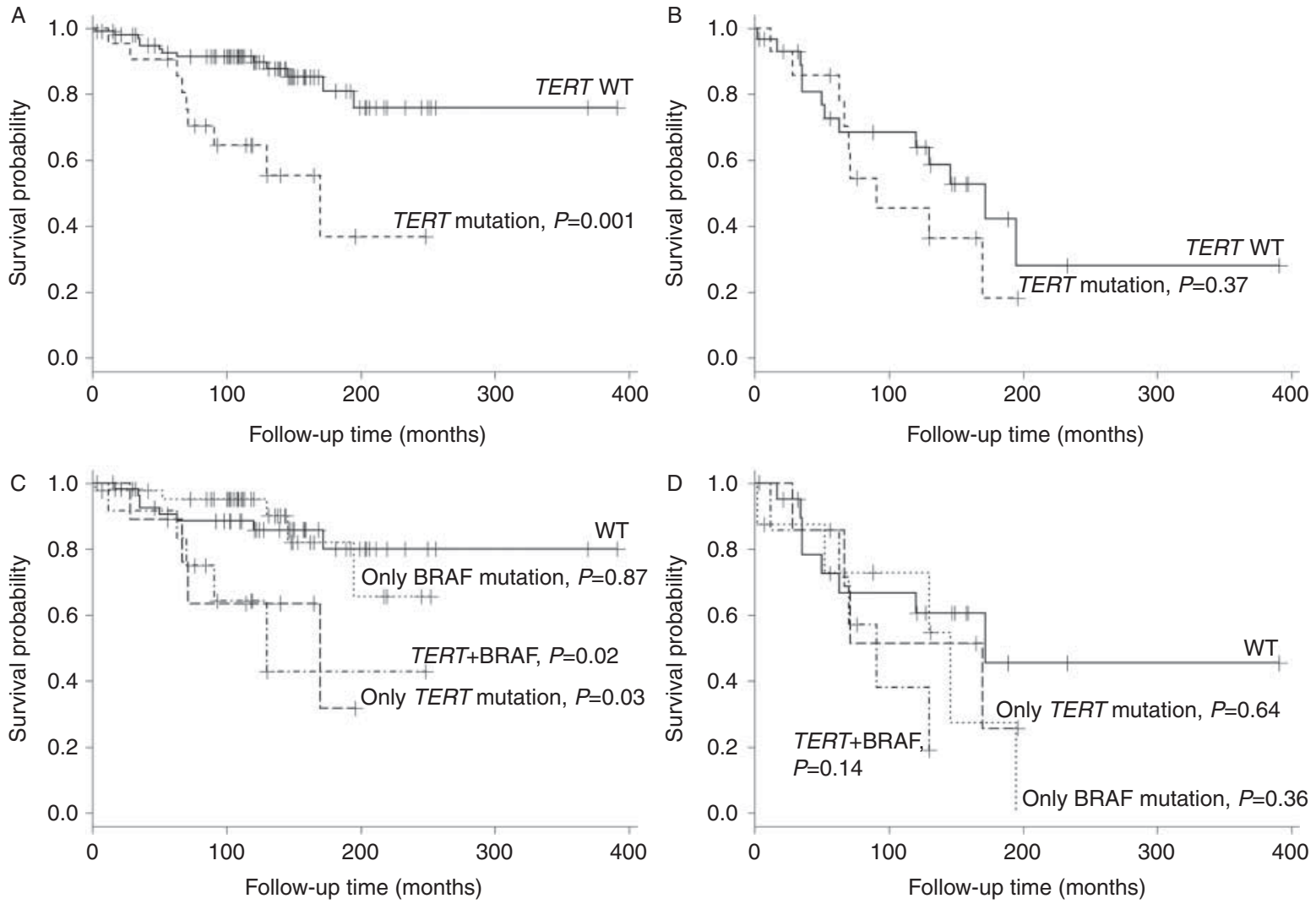

\section{Figure 2}

(A and B) Kaplan-Meier curves of thyroid carcinoma-specific survival by TERT mutation status in the overall PTCs cases analyzed in this study $(n=121, \mathrm{~A})$ and in DM-PTCs only $(n=43, \mathrm{~B})$. (C and D) Kaplan-Meier curves of thyroid carcinoma-specific survival by TERT mutation, BRAF mutation, and their coexistence status in the overall PTCs cases analyzed in this study $(n=121$, C) and in DM-PTCs only $(n=43, \mathrm{D})$. Survival curves were compared by log-rank test, using the WT as reference. The $P<0.05$ were considered as threshold for significance. The $P$ values of the comparison between TERT+BRAF-double mutants and TERT single-mutant was nonsignificant (0.90), while the comparison between TERT+BRAF-double mutants and BRAF single-mutant was significant (0.02).

only TERT or both TERT and BRAF mutations showed a significantly lower survival probability compared with WT PTCs (log-rank $P=0.02$ and $P=0.03$ respectively), while BRAF mutation status alone did not affect the survival (Fig. 2C). Again, we did not observe any significant difference in the survival curves when performing the same analysis within the DM-PTC group (Fig. 2D).

Finally, we evaluated the effect on survival of the co-occurrence of both BRAF and TERT promoter mutations as compared with the occurrence of $B R A F$ or TERT promoter single mutants (Fig. 2C).

We did not observe a significant effect of the BRAF V600E mutation on the survival curve of TERT mutated tumors $(P=0.90)$. By contrast, the presence of TERT mutations strongly decreased the survival probability of BRAF V600E mutated PTC patients $(P=0.02)$.

\section{Discussion}

Well-differentiated PTCs are usually indolent lesions with low rate of growth and low metastatic potential. Nonetheless, a small but significant percentage of PTCs (5-10\%) behave aggressively, developing metastases and possibly leading to patient's death $(2,3,29)$. The identification of prognostic markers able to discriminate aggressive PTCs from those with an indolent course would be of great relevance to better tailor the therapeutic approach and the long-term surveillance, avoiding overtreatment (34). The relative rarity of aggressive PTCs and the slow course of this disease make it difficult to collect large cohorts of tumors with distant metastases, which is necessary to obtain a more exhaustive comprehension of the genetic and biological processes at the basis of the metastatic 
spreading of these tumors and to improve the current prognostic capacity in the diagnosis of PTCs.

In this study, we analyzed a cohort of 43 DM-PTCs and we showed that mutation in the TERT promoter is a frequent event in metastatic tumors. Indeed, the occurrence of TERT mutations was more than 3.5-fold higher (33\% vs 9\%) in the group of DM-PTCs as compared with the control group of nonaggressive tumors. The high prevalence of these alterations in aggressive PTCs indicates that TERT promoter mutations, in particular the C228T mutation, could be a promising marker for risk stratification of PTC patients.

This is one of the first studies in which the occurrence of TERT promoter mutations is directly correlated with the presence of distant metastases in PTC. Two recent studies $(27,33)$ have analyzed TERT promoter mutations in large PTC sets, which included also a subset of patients who developed metastases at distant sites (36 and 22 cases respectively). Melo et al. (27) described not only a strong association between the presence of TERT promoter mutations and a low grade of differentiation of the tumors, but also a significant association between the presence of the mutations and the development of distant metastases in well-differentiated thyroid cancer, including PTCs and follicular thyroid carcinoma (FTCs) cases. This association was not significant in the PTCs subgroup only, albeit it tended to significance. In another study, Xing et al. (33) found a significantly higher frequency (45\%) of the C228T mutation in 22 PTCs with distant metastases as compared with the one detected in PTCs without distant metastases (10\%). Our observation in a larger DM-PTC set extends and supports these data, confirming that TERT promoter mutations are major genetic features of PTCs with metastatic behavior, and sustaining the hypothesis that these alterations may play a relevant role in determining the progression of thyroid cancer.

In our analysis, TERT promoter mutations were also associated with an older age at diagnosis and with the TCV-PTC histotype, which is a more aggressive variant compared with classic PTCs and follicular-variant PTCs, in agreement with previously published data (24). Furthermore, we observed a strong association between the presence of these mutations and increased diseaserelated mortality when considered the overall cohort of samples in analysis.

Taken together, these data indicate that TERT promoter mutations, in particular the C228T mutation, are major genetic events during the acquisition of metastatic potential in thyroid cancer. However, the fact that the disease-related mortality within the DM-PTCs was not related with TERT mutations seems to suggest that once the metastatic behavior has been acquired, the TERT status does not affect the outcome of the patients.

It has been reported that TERT promoter mutations are able to increase the transcriptional activity of the promoter $(12,13,18)$, and that TERT-mutated tumors express higher level of TERT mRNA compared with WT-tumors $(17,18,19,20,35)$. TERT is a reverse transcriptase involved in the maintenance of the integrity of telomere length. In normal, actively proliferating cells, the progressive shortening of telomeres leads eventually to replicative senescence. In this regard, it is conceivable that the acquisition of features leading to TERT activation is an important event during cancer progression, as it allows tumor cells to avoid proliferation limitation and to acquire immortalization (21). Furthermore, telomereindependent activities of TERT have been reported and several studies showed that this protein is engaged in processes such as regulation of DNA damage response, repression of apoptosis, regulation of chromatin state, and enhanced cell proliferation that are important for cancer progression $(36,37,38,39,40)$.

In the aggressive DM-PTCs group, we found that C228T mutation tended to be prevalent in tumors harboring also the BRAF V600E mutation, while this association was not evaluable in control-PTCs due to the small number of TERT-mutated cases. Association between TERT and BRAF mutation has been previously reported $(24,26,27,33)$ and it has been proposed that their coexistence may define a more aggressive subgroup of PTC (33). Our results suggest that TERT promoter mutations are associated with the presence of distant metastases independently from the BRAF status, which is not predictive, alone or in association with TERT mutations, with aggressive behavior in our cohort, as previously described $(31,32)$.

Moreover, we found that the occurrence of TERT promoter mutations decrease the disease-specific survival of BRAF V600E mutated tumors, while the presence of BRAF V600E mutation did not affect significantly the outcome of TERT-mutated PTCs.

In conclusion, TERT promoter mutations, and in particular TERT C228T, were found to be strongly associated with tumor progression and development of distant metastases in PTCs. When confirmed by larger, prospective studies on consecutive cases, these findings may help in elucidating the usefulness of TERT as a prognostic marker of aggressive behavior in this cancer. 


\section{Declaration of interest}

The authors declare that there is no conflict of interest that could be perceived as prejudicing the impartiality of the research reported.

\section{Funding}

This work was partially supported by a grant from the Italian Ministry of Health (GR-2011-02350937). G Gandolfi is supported by a Fondazione Umberto Veronesi Post-Doctoral Fellowship.

\section{Acknowledgements}

The authors thank the Thyroid Research Audit for Innovation (T.R.A.I.N.) group of the Arcispedale S. Maria Nuova-IRCCS.

\section{References}

1 Davies L \& Welch HG. Increasing incidence of thyroid cancer in the United States, 1973-2002. Journal of the American Medical Association 2006295 2164-2167. (doi:10.1001/jama.295.18.2164)

2 Pellegriti G, Frasca F, Regalbuto C, Squatrito S \& Vigneri R. Worldwide increasing incidence of thyroid cancer: update on epidemiology and risk factors. Journal of Cancer Epidemiology 20132013965212. (doi:10.1155/2013/965212)

3 Davies L \& Welch HG. Current thyroid cancer trends in the United States. JAMA Otolaryngology - Head \& Neck Surgery 2014140 317-322. (doi:10.1001/jamaoto.2014.1)

4 Kondo T, Ezzat S \& Asa S. Pathogenetic mechanisms in thyroid follicular-cell neoplasia. Nature Reviews. Cancer 20066 292-306. (doi:10.1038/nrc1836)

5 Handkiewicz-Junak D, Czarniecka A \& Jarzab B. Molecular prognostic markers in papillary and follicular thyroid cancer: current status and future directions. Molecular and Cellular Endocrinology 2010322 8-28. (doi:10.1016/j.mce.2010.01.007)

6 Haq M \& Harmer C. Differentiated thyroid carcinoma with distant metastases at presentation: prognostic factors and outcome. Clinical Endocrinology 200563 87-93. (doi:10.1111/j.1365-2265.2005.02304.x)

7 Li C, Lee KC, Schneider EB \& Zeiger MA. BRAF V600E mutation and its association with clinicopathological features of papillary thyroid cancer: a meta-analysis. Journal of Clinical Endocrinology and Metabolism 201297 4559-4570. (doi:10.1210/jc.2012-2104)

8 Hanahan D \& Weinberg RA. Hallmarks of cancer: the next generation. Cell 2011144 646-674. (doi:10.1016/j.cell.2011.02.013)

9 Greider CW \& Blackburn EH. Identification of a specific telomere terminal transferase activity in Tetrahymena extracts. Cell 198543 405-413. (doi:10.1016/0092-8674(85)90170-9)

10 Collins K. The biogenesis and regulation of telomerase holoenzymes. Nature Reviews. Molecular Cell Biology 20067 484-494. (doi:10.1038/ nrm1961)

11 Harley CB. Telomerase and cancer therapeutics. Nature Reviews. Cancer 20088 167-179. (doi:10.1038/nrc2275)

12 Horn S, Figl A, Rachakonda PS, Fischer C, Sucker A, Gast A, Kadel S, Moll I, Nagore E, Hemminki K et al. TERT promoter mutations in familial and sporadic melanoma. Science 2013339 959-961. (doi:10. 1126/science.1230062)

13 Huang FW, Hodis E, Xu MJ, Kryukov GV, Chin L \& Garraway LA. Highly recurrent TERT promoter mutations in human melanoma. Science 2013339 957-959. (doi:10.1126/science.1229259)

14 Killela PJ, Reitman ZJ, Jiao Y, Bettegowda C, Agrawal N, Diaz LA Jr, Friedman AH, Friedman H, Gallia GL, Giovanella BC et al. TERT promoter mutations occur frequently in gliomas and a subset of tumors derived from cells with low rates of self-renewal. PNAS $2013 \mathbf{1 1 0}$ 6021-6026. (doi:10.1073/pnas.1303607110)

15 Kinde I, Munari E, Faraj SF, Hruban RH, Schoenberg M, Bivalacqua T, Allaf M, Springer S, Wang Y, Diaz LA et al. TERT promoter mutations occur early in urothelial neoplasia and are biomarkers of early disease and disease recurrence in urine. Cancer Research 201373 7162-7167. (doi:10.1158/0008-5472.CAN-13-2498)

16 Liu X, Wu G, Shan Y, Hartmann C, von Deimling A \& Xing M. Highly prevalent TERT promoter mutations in bladder cancer and glioblastoma. Cell Cycle 201312 1637-1638. (doi:10.4161/cc.24662)

17 Nault JC, Mallet M, Pilati C, Calderaro J, Bioulac-Sage P, Laurent C, Laurent A, Cherqui D, Balabaud C \& Zucman-Rossi J. High frequency of telomerase reverse-transcriptase promoter somatic mutations in hepatocellular carcinoma and preneoplastic lesions. Nature Communications 20134 2218. (doi:10.1038/ncomms3218)

18 Rachakonda PS, Hosen I, de Verdier PJ, Fallah M, Heidenreich B, Ryk C, Wiklund NP, Steineck G, Schadendorf D, Hemminki K et al. TERT promoter mutations in bladder cancer affect patient survival and disease recurrence through modification by a common polymorphism. PNAS 2013110 17426-17431. (doi:10.1073/pnas.1310522110)

19 Tallet A, Nault JC, Renier A, Hysi I, Galateau-Salle F, Cazes A, Copin MC, Hofman P, Andujar P, Le Pimpec-Barthes F et al. Overexpression and promoter mutation of the TERT gene in malignant pleural mesothelioma. Oncogene 201333 3748-3752. (doi:10.1038/onc.2013.351)

20 Vinagre J, Almeida A, Populo H, Batista R, Lyra J, Pinto V, Coelho R, Celestino R, Prazeres H, Lima L et al. Frequency of TERT promoter mutations in human cancers. Nature Communications 201342185 (doi:10.1038/ncomms3185)

21 Heidenreich B, Nagore E, Rachakonda PS, Garcia-Casado Z, Requena C, Traves V, Becker J, Soufir N, Hemminki K \& Kumar R. Telomerase reverse transcriptase promoter mutations in primary cutaneous melanoma. Nature Communications 20145 3401. (doi:10.1038/ ncomms4401)

22 Wu RC, Ayhan A, Maeda D, Kim KR, Clarke BA, Shaw P, Chui MH, Rosen B, Shih Ie M \& Wang TL. Frequent somatic mutations of the telomerase reverse transcriptase promoter in ovarian clear cell carcinoma but not in other major types of gynaecological malignancy. Journal of Pathology 2014232 473-481. (doi:10.1002/path.4315)

23 Landa I, Ganly I, Chan TA, Mitsutake N, Matsuse M, Ibrahimpasic T, Ghossein RA \& Fagin JA. Frequent somatic TERT promoter mutations in thyroid cancer: higher prevalence in advanced forms of the disease. Journal of Clinical Endocrinology and Metabolism 201398 E1562-E1566. (doi:10.1210/jc.2013-2383)

24 Liu X, Bishop J, Shan Y, Pai S, Liu D, Murugan AK, Sun H, El-Naggar AK $\&$ Xing M. Highly prevalent TERT promoter mutations in aggressive thyroid cancers. Endocrine-Related Cancer 201320 603-610. (doi:10. 1530/ERC-13-0210)

25 Liu T, Wang N, Cao J, Sofiadis A, Dinets A, Zedenius J, Larsson C \& $\mathrm{Xu} \mathrm{D}$. The age- and shorter telomere-dependent TERT promoter mutation in follicular thyroid cell-derived carcinomas. Oncogene 2014 33 4978-4984. (doi:10.1038/onc.2013.446)

26 Liu X, Qu S, Liu R, Sheng C, Shi X, Zhu G, Murugan AK, Guan H, Yu H, Wang $\mathrm{Y}$ et al. TERT promoter mutations and their association with BRAF V600E mutation and aggressive clinicopathological characteristics of thyroid cancer. Journal of Clinical Endocrinology and Metabolism 201499 E1130-E1136. (doi:10.1210/jc.2013-4048)

27 Melo M, da Rocha AG, Vinagre J, Batista R, Peixoto J, Tavares C, Celestino R, Almeida A, Salgado C, Eloy C et al. TERT promoter mutations are a major indicator of poor outcome in differentiated thyroid carcinomas. Journal of Clinical Endocrinology and Metabolism 201499 E754-E765. (doi:10.1210/jc.2013-3734)

28 Vinagre J, Pinto V, Celestino R, Reis M, Pópulo H, Boaventura P, Melo M, Catarino T, Lima J, Lopes JM et al. Telomerase promoter mutations in cancer: an emerging molecular biomarker? Virchows Archiv 2014465 119-133. (doi:10.1007/s00428-014-1608-4) 
29 De Lellis RA, Lloyd RV, Heitz PU \& Eng C. In World Health Organization Classification of Tumours. Pathology and Genetics of Tumors of Endocrine Organs, 1st edn, Lyon, France: IARC Press, 2004.

30 Edge SB, Compton CC \& Fritz AG. In AJCC Cancer Staging Manual, 7th edn, New York: Springer, 2010.

31 Sancisi V, Nicoli D, Ragazzi M, Piana S \& Ciarrocchi A. BRAFV600E mutation does not mean distant metastasis in thyroid papillary carcinomas. Journal of Clinical Endocrinology and Metabolism 201297 E1745-E1749. (doi:10.1210/jc.2012-1526)

32 Gandolfi G, Sancisi V, Torricelli F, Ragazzi M, Frasoldati A, Piana S \& Ciarrocchi A. Allele percentage of the BRAF V600E mutation in papillary thyroid carcinomas and corresponding lymph node metastases: no evidence for a role in tumor progression. Journal of Clinical Endocrinology and Metabolism 201398 E934-E942. (doi:10.1210/jc.2012-3930)

33 Xing M, Liu R, Liu X, Murugan AK, Zhu G, Zeiger MA, Pai S \& Bishop J. BRAF V600E and TERT promoter mutations cooperatively identify the most aggressive papillary thyroid cancer with highest recurrence. Journal of Clinical Oncology 201432 2718-2726. (doi:10.1200/JCO.2014. 55.5094)

34 Esserman LJ, Thompson IM Jr \& Reid B. Overdiagnosis and overtreatment in cancer: an opportunity for improvement. Journal of the American Medical Association 2013310 797-798. (doi:10.1001/jama.2013.108415)
35 Arita H, Narita Y, Fukushima S, Tateishi K, Matsushita Y, Yoshida A, Miyakita Y, Ohno M, Collins VP, Kawahara N et al. Upregulating mutations in the TERT promoter commonly occur in adult malignant gliomas and are strongly associated with total $1 \mathrm{p} 19 \mathrm{q}$ loss. Acta Neuropathologica 2013126 267-276. (doi:10.1007/s00401-013-1141-6)

36 Del Bufalo D, Rizzo A, Trisciuoglio D, Cardinali G, Torrisi MR, ZangemeisterWittke $\mathrm{U}$, Zupi G \& Biroccio A. Involvement of hTERT in apoptosis induced by interference with Bcl-2 expression and function. Cell Death and Differentiation 200512 1429-1438. (doi:10.1038/sj.cdd.4401670)

37 Masutomi K, Possemato R, Wong JM, Currier JL, Tothova Z, Manola JB, Ganesan S, Lansdorp PM, Collins K \& Hahn WC. The telomerase reverse transcriptase regulates chromatin state and DNA damage responses. PNAS 2005102 8222-8227. (doi:10.1073/pnas.0503095102)

38 Rahman R, Latonen L \& Wiman KG. hTERT antagonizes p53-induced apoptosis independently of telomerase activity. Oncogene 200524 1320-1327. (doi:10.1038/sj.onc.1208232)

39 Calado RT \& Chen J. Telomerase: not just for the elongation of telomeres. BioEssays: News and Reviews in Molecular, Cellular and Developmental Biology 200628 109-112. (doi:10.1002/bies.20365)

40 Parkinson EK, Fitchett C \& Cereser B. Dissecting the non-canonical functions of telomerase. Cytogenetic and Genome Research 2008122 273-280. (doi:10.1159/000167813)

Received 3 October 2014

Revised version received 17 November 2014

Accepted 12 January 2015 